\title{
Thermochemical Properties of Glass Wool/Maerogel Composites
}

\author{
Bahador Dastorian Jamnani, ${ }^{1}$ Soraya Hosseini, ${ }^{1}$ \\ Amin Shavandi, ${ }^{2}$ and Mohd Roshdi Hassan ${ }^{3}$ \\ ${ }^{1}$ Department of Engineering, University of Malaya, Kuala Lumpur, Malaysia \\ ${ }^{2}$ Centre for Material Science and Technology, University of Otago, Dunedin, New Zealand \\ ${ }^{3}$ Department of Engineering, Universiti Putra Malaysia, Selangor, Malaysia \\ Correspondence should be addressed to Amin Shavandi; amin.shavandi@postgrad.otago.ac.nz
}

Received 14 July 2016; Revised 25 October 2016; Accepted 31 October 2016

Academic Editor: Kohji Tashiro

Copyright (C) 2016 Bahador Dastorian Jamnani et al. This is an open access article distributed under the Creative Commons Attribution License, which permits unrestricted use, distribution, and reproduction in any medium, provided the original work is properly cited.

\begin{abstract}
Aerogel blankets are composites of silica aerogel particles dispersed in a reinforcing fiber matrix that turns the brittle aerogel into durable and flexible insulating materials. In this study, silica aerogel was loaded on glass wool with different concentrations $(0-$ 18.6\%) and morphological and thermal characteristics of the aerogel blankets were studied. Rate of modified blanket decomposition was slower at temperatures between $250^{\circ} \mathrm{C}$ and $650^{\circ} \mathrm{C}$ due to the retardant effect of the silica aerogel. The average diameter of the fiber for either original glass wool or modified glass wool materials was approximately $20 \mu \mathrm{m}$ and samples had porous, interconnected particles with dendritic-like structure.
\end{abstract}

\section{Introduction}

With the continuous rise in energy consumption, limited supply of fossil fuels, global warming, and climate issues, both governments and industry sectors are looking for alternative or improved thermal systems by employing high performance insulation materials. Aerogel, invented by Kistler [1] in 1932, is one of the insulation materials which are yet to be exploited onto the industrial level. Within the classification of aerogels, silica aerogel exhibits the most attractive physical characteristics such as low thermal conductivity $(\sim 0.015 \mathrm{~W} / \mathrm{mK})$, low bulk density $\left(\sim 0.1 \mathrm{~g} / \mathrm{cm}^{3}\right)$, optical transparency in the visible spectrum ( $\sim 99 \%)$, high specific surface area $\left(\sim 1000 \mathrm{~m}^{2} / \mathrm{g}\right)$, low dielectric constant $(\sim 1.0-2.0)$, low refractive index $(\sim 1.05)$, low sound velocity $(100 \mathrm{~m} / \mathrm{s})$, and hydrophobicity [2]. Researchers have already recognized the superiority of this frozen-smoke -like solid (aerogel) over conventional materials such as glass wool [3]. In parallel, tremendous efforts have been done to increase the cost efficiency in the preparation of aerogels due to the high investment attributed to the precursor of silica and the supercritical drying process [4]. In 2007, an aerogel, commercially known as Maerogel ${ }^{\circledR}$, derived from an agricultural waste product, was invented; thereby the silica was extracted from rice husk ash followed by a sol-gel mechanism and supercritical drying [5]. It is claimed that the production cost was cut by around $80 \%$ compared to the traditional silica aerogel $[4,5]$. Although an aerogel can be manufactured in powder, monoliths, or films, the design of composite aerogel blankets, which consists of dispersing the silica aerogel particles into a reinforcing fiber matrix, eventually prevents any damage to the brittle aerogel matrix and so allows it to be applied into the extreme surroundings where mechanical loads are significant. In this work, glass wool/Maerogel, nonwoven composites were synthesized by a sol-gel approach followed by both ambient and high-temperature heat treatments. The thermal and morphological properties of the samples were then investigated.

\section{Experimental Details}

2.1. Preparation of Silica Sol. The silica sol was prepared using rice husk ash (RHA) as the precursor of silica. $39.13 \mathrm{~g}$ of RHA was mixed and stirred together with $14.55 \mathrm{~g}$ of sodium hydroxide and $450 \mathrm{~g}$ of water in a Teflon bottle at $90^{\circ} \mathrm{C}$ for 2 days. The mixture was then filtrated by passing through an ion 


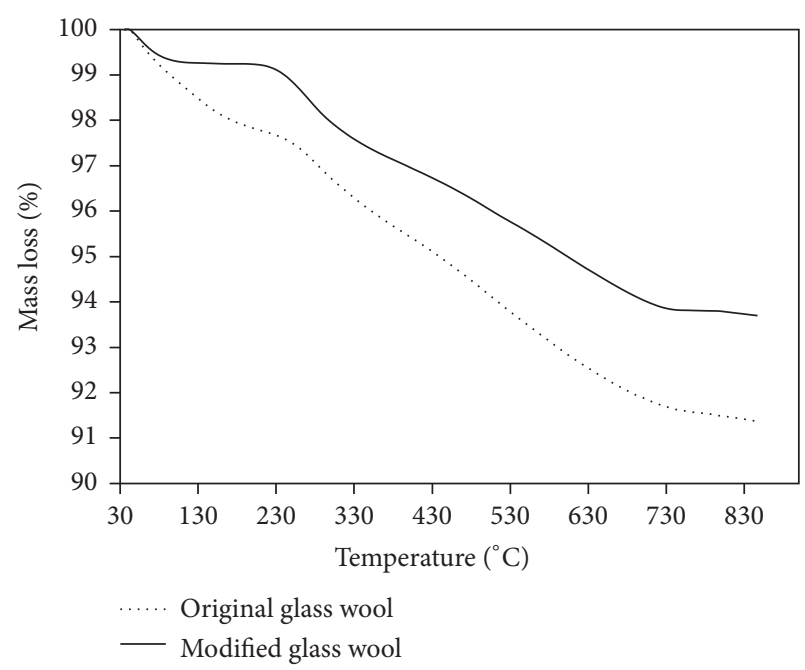

(a)

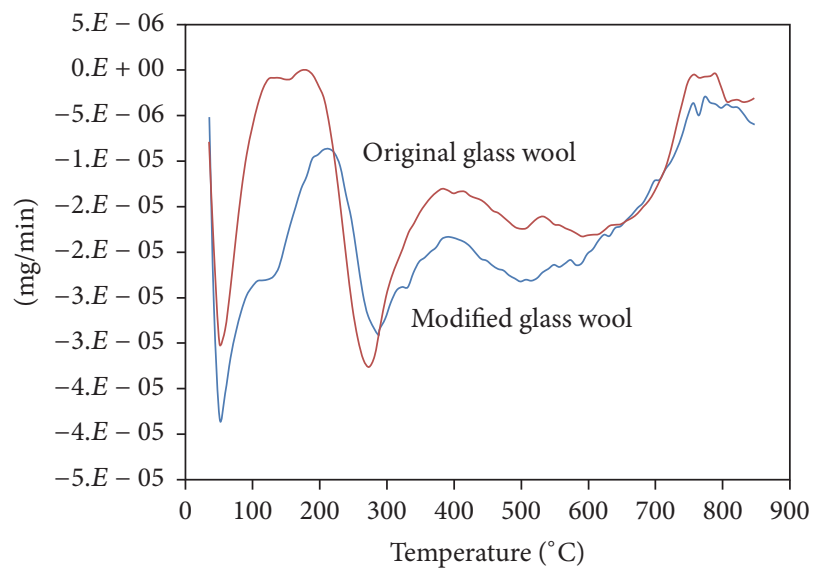

(b)

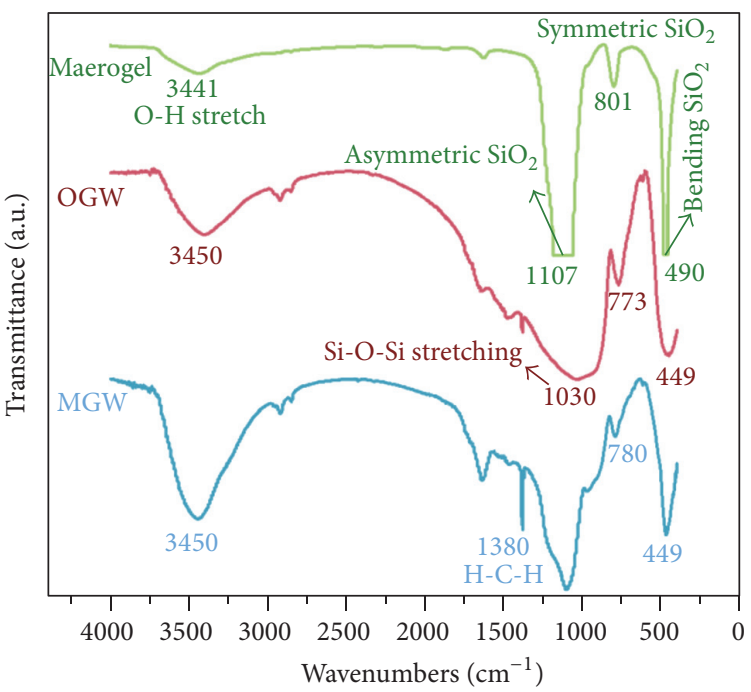

(c)

FIgUre 1: TGA (a). DTG (b). and FTIR (c). Comparison between original glass wool (OGW) and modified glass wool (MGW).

exchange column $($ diameter $=10 \mathrm{~cm}$; length $=40 \mathrm{~cm}$ ) filled with Amberlite resin. The rate of passing the mixture through the column was controlled by a micromotor. The collected filtrate was sodium silicate with a $\mathrm{pH}$ value of 2-3. The latter was mixed with ethanol $(1: 1 \mathrm{v} / \mathrm{v})$ and the percentage of silica in the solution was found to be $6 \mathrm{wt} \%$. pH was adjusted to 5 using ammonium hydroxide.

2.2. Preparation of Maerogel Blanket. Original glass wool was cut and shaped into the $35 \mathrm{~g}$ cuboids with dimensions of $9.5 \mathrm{~cm} \times 12.5 \mathrm{~cm} \times 5 \mathrm{~cm}$ length, width, and thickness, respectively. Different fabrications of the blankets were made by using various concentrations of the silica ethanol and tetraethyl orthosilicate (TEOS) (Table 1). The basic glass wool samples were moistened using the obtained mixtures and then kept in an oven for gelation at $50^{\circ} \mathrm{C}$ for $3 \mathrm{~h}$. After gelation, the wet blankets were soaked in $200 \mathrm{~mL}$ of ethanol
TABLE 1: The different loaded Maerogels.

\begin{tabular}{lccccc}
\hline & Case & Case & Case & Case & Case \\
& 0 & 1 & 2 & 3 & 4 \\
\hline $\begin{array}{l}\text { Weight\% } \\
\text { Loaded Maerogel (gr)/total } \\
\text { weight after drying (gr) }\end{array}$ & 0 & 5.4 & 10.2 & 14.6 & 18.6 \\
\hline
\end{tabular}

solution and aged at room temperature for $48 \mathrm{~h}$; then a solvent exchange solution of $167 \mathrm{~mL}$-hexane, $17 \mathrm{~mL}$ tetramethyl chlorosilane, and $10 \mathrm{~mL}$ of isopropyl alcohol was added to the blankets in the ethanol solution and was further aged for $48 \mathrm{~h}$ at room temperature. The wet gel blanket was then taken out and dried at atmospheric conditions for $24 \mathrm{~h}$ and further dried at $60^{\circ} \mathrm{C}$ for $4 \mathrm{~h}$, followed by a heat treatment at $230^{\circ} \mathrm{C}$ for $2 \mathrm{~min}$. The dried blankets were weighted to calculate the loaded Maerogel on each sample. 
2.3. Sample Characterizations. Thermogravimetric analysis (TGA) was carried out suing a Mettler Toledo TGA/DSC1. The runs were performed at a rate of $10^{\circ} \mathrm{C} / \mathrm{min}$ from 30 to $850^{\circ} \mathrm{C}$ under dry air atmosphere. The functional groups of the samples were identified using FTIR $(\mathrm{KBr})$ over the region of $400-4,000 \mathrm{~cm}^{-1}$ with a $2 \mathrm{~cm}^{-1}$ spectral resolution by a FTS3000 spectrometer. The microstructure of the silica aerogel blanket was investigated using Scanning Electron Microscopy (SEM, HITACHI, Japan) at $10 \mathrm{kV}$. Prior to its observation, the samples were cryofractured and sputtercoated with a thin layer of gold. The thermal resistance of the modified blankets was analysed by exposing the bottom surface to a hot plate (Fisher Scientific Isotemp Digital) and the top surface to ambient temperature. Two J type thermocouples were placed at the middle section of each face and the temperatures were retrieved using a data logger interface coupled with VEE software.

\section{Results and Discussion}

3.1. Thermogravimetric Analysis (TGA). Case 4 contains the highest loaded Maerogel (18.6 wt\%) that could be possible on the blanket; therefore, it was considered as the optimum sample or modified glass wool (MGW) and is selected for comparison with original glass wool (OGW). The TGA thermogram of the samples is shown in Figure 1(a). The first descent at around $52^{\circ} \mathrm{C}$ could be due to decomposition or evaporation of water from both samples. As shown, the weight loss mechanism was delayed by the modified glass wool from $97.5 \%$ to $99.5 \%$ (Figure 1). Additionally, the presence of Maerogel hinders the heat transfer rate due to an increase in the amount of ash formation which consequently acts as a heat barrier and consequently the thermal stability of the silica aerogel blanket was better compared to the OGW. These results are in accordance with previously reported results which reported that silica aerogel could increase the rate of ash formation which was known to act as insulator between the flame and the burning material [6].

3.2. Derivative Thermogravimetry (DTG). As can be seen in Figure 1(b), the OGW began to decompose at onset and peak at $179^{\circ} \mathrm{C}$ and $270^{\circ} \mathrm{C}$, respectively, while the $\mathrm{MGW}$ started to decompose at $213^{\circ} \mathrm{C}$ and $287^{\circ} \mathrm{C}$ for onset and peak, respectively. It is interpreted that $\mathrm{MGW}$ is reasonably able to retard processing loss weight from 270 to $287^{\circ} \mathrm{C}$. Zhu et al. [7] have demonstrated a synergistic effect of silica aerogel with temperature increments of about $12^{\circ} \mathrm{C}-17^{\circ} \mathrm{C}$. At temperatures higher than $270^{\circ} \mathrm{C}$, the addition of silica aerogel reduced the rate of weight loss of the blanket. Doping with silica aerogel particles caused the weight loss to change slightly compared with OGW sample, which was associated with an increase in the amount of silica ash generated during the test which effectively improves thermal stability of the silica aerogel blanket. The curves also show that thermal degradation began to occur only after the materials have absorbed certain amounts of heat energy. The heat initiated the degradation processes and the breaking down of the fibers and matrix structure by causing molecular chain ruptures or scission [8].
TABLE 2: Wavenumber assignments for the spectra of the Maerogel, OGW, and MGW samples.

\begin{tabular}{lccc}
\hline Functional group & Maerogel (pure) & (OGW) & $(\mathrm{MGW})$ \\
\hline $\mathrm{SiO}_{2}$ asymmetric & 1107 & - & - \\
$\mathrm{SiO}_{2}$ symmetric & 862 & 773 & 793 \\
$\mathrm{Si}^{-} \mathrm{OCH}_{2} \mathrm{CH}_{3}$ & $1165-990$ & - & - \\
$\mathrm{SiO}_{2}$ bending & 490 & 449 & 469 \\
$\mathrm{Si}-\mathrm{O}$ bending & 865 & 773 & 793 \\
$\mathrm{Si}-\mathrm{O}-\mathrm{Si}$ stretching & 1083 & 1030 & 1100 \\
$\mathrm{C}-\mathrm{H}$ bending & - & - & 1380 \\
\hline
\end{tabular}

3.3. Fourier Transform Infrared (FTIR). Wavenumber assignments for the spectra of the Maerogel, OGW, and MGW samples are shown in Table 2 and Figure 1(c). These indicate that the samples contain a number of atomic groupings and structures. For Maerogel, a broad peak appears at $3441 \mathrm{~cm}^{-1}$ assigned to $\mathrm{O}-\mathrm{H}$ stretching due to adsorbed water, $\mathrm{H}$-bridging hydroxyl (-Si-OH $\cdots \mathrm{O}-\mathrm{Si}$-) group, and isolated (-Si-OH). A small peak at $1630-1640 \mathrm{~cm}^{-1}$ is assigned to alkene $(\mathrm{C}=\mathrm{C})$ group. The spectrum also shows strong peaks at around 1107,801 , and $490 \mathrm{~cm}^{-1}$ due to asymmetric, symmetric, and bending modes of $\mathrm{SiO}_{2}$, respectively, typical of silica material. Presence of the silica materials in the composite might have a synergistic effect which results in a $12-17^{\circ} \mathrm{C}$ increment in the temperature. The similar result was reported regarding to Maerogel [9]. Neither the OGW nor the Maerogel peaks disappeared, although an extra peak was found at $1380 \mathrm{~cm}^{-1}$ in comparison with Maerogel and OGW. This peak was related to bending $\mathrm{H}-\mathrm{C}-\mathrm{H}$. The existence of $\mathrm{C}-\mathrm{H}$ band in the spectrum indicated that composition of TEOS was well linked inside glass wool in order to produce a network for supporting Maerogel particles. All samples follow almost the same trend due to their similarity in the chemical bonds. Peaks near 1100 and $800 \mathrm{~cm}^{-1}$ were attributed to $\mathrm{Si}-\mathrm{O}-\mathrm{Si}$, which can associate with the lower weight loss of these samples during thermal analysis. These peaks form the internal network structure of the samples; the results suggest that presence of silica in the samples matrix increases the surface contact area between the matrix and silica particles and results in an increase in the heat energy adsorption during the process of decomposition. The $3400 \mathrm{~cm}^{-1}$ peaks indicated $(-\mathrm{OH})$ bonding due to the presence of ethoxy groups (-OC2 $\mathrm{H} 5$ ) and $870 \mathrm{~cm}^{-1}$ peaks (C$\mathrm{H})$ bonding due to the presence of Si-CH3 [10]. In accordance with thermal analysis results at elevated temperature, possible migration of these silica bonding chars to the surface of the composite can act as heat barrier and result in higher heat stability of the composite [9].

3.4. Morphological Properties (SEM). SEM micrographs were taken to exhibit the microstructure and bonding process of glass wool and Maerogel materials. These flexible aerogel blankets were fiber-reinforced composite materials containing fiber-based thermal insulation impregnated with aerogels. As shown in the SEM image, glass wool fibers are stratified randomly in more or less parallel planes between the 


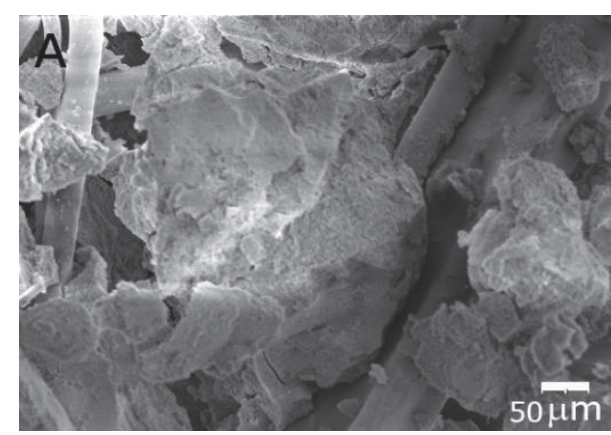

(a)

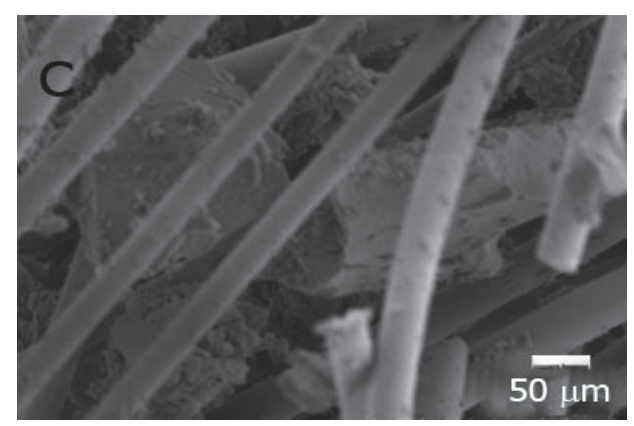

(c)

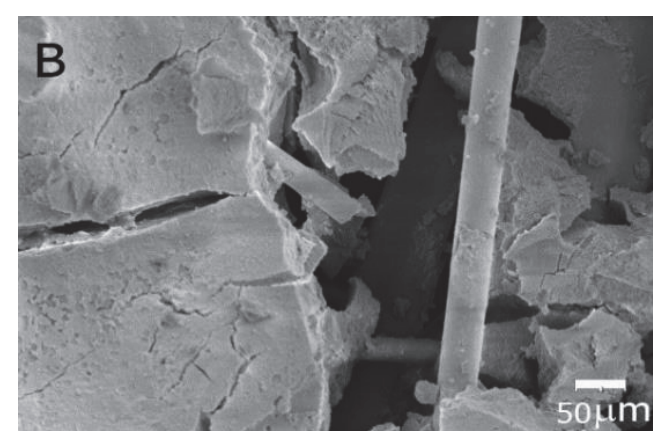

(b)

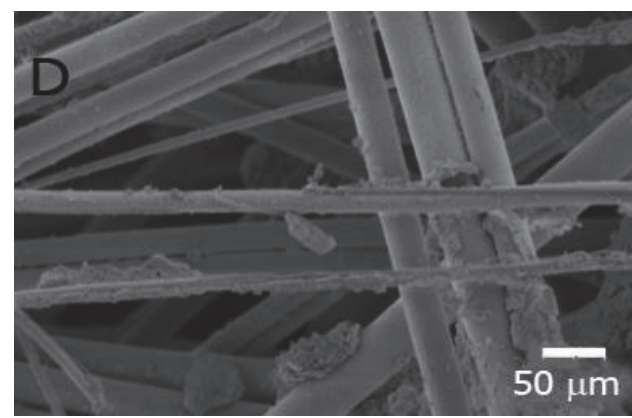

(d)

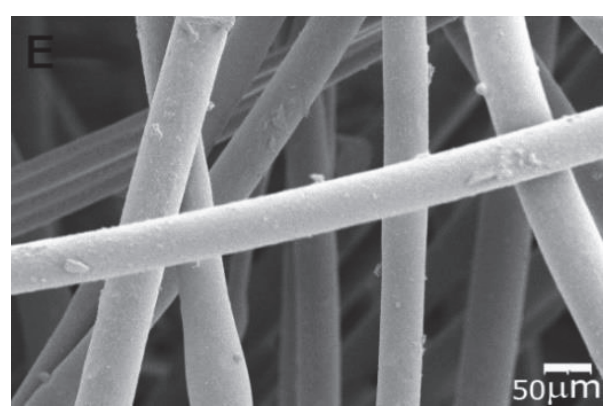

(e)

FIGURE 2: SEM images of different loaded Maerogel on glass wool: (a) case 4, (b) case 3, (c) case 2, (d) case 1, and (e) OGW without loaded Maerogel.

medium boundaries. The microstructure of aerogel blanket materials was characterized by the existence of many fibers and various aerogel particles of different sizes. In fact, the fibers were surrounded by many aerogels particles. There were also some aerogel particles along the surface of the fibers. The difference between the microstructures of modified glass wool materials can be explained by factors such as the preparation conditions and the concentration of precursors. The average diameter of the fiber for either original glass wool or modified glass wool materials is approximately $20 \mu \mathrm{m}$. The composites with higher amount of Maerogel appeared to be homogenous; however, samples with lower Maerogel content showed cracks and fractures, and in this case there was poor interaction between the glass wool and Maerogel. In addition, it was not experimentally possible to load more than $18.6 \%$ Maerogel into the glass wool fiber. As shown in the SEM images (Figure 2), the heterogeneity of the material could be the reason of cracks observed on the sample surface. Aerogel networks are formed from open colloidal particles. These particles were interconnected in a highly porous, dendritic-like structure. The structure of aerogel is three-dimensional including many pores whose diameter ranges from $10 \mathrm{~nm}$ to $15 \mathrm{~nm}$. The fibers are randomly oriented and are incorporated into aerogel blanket matrices. The fiber's contact points are bonded together. The strength of the blanket materials is determined by the strength of the fibers, the strength of the bonding between the fibers, the strength of the aerogel network, and the form of loading. Consequently, the deformation of the fibers will limit the strength of the insulation materials [8]. Better heat stability of the modified glass wool fiber can be associated with the presence and formation of voids in the composite structure which act as air pockets and provide a heat barrier layer in the material. In the SEM images of OGW and MGW, fibers, the air pockets, and aerogel particles can be identified. During the incorporation of fibers into the silica aerogels or during 
the manufacturing of aerogel blankets, air or other volatiles are trapped in the blanket material. The existence of the trapped air or other volatiles in the perfect blanket is in the form of pockets or microvoids which may be visible without destroying the blanket. SEM images of Maerogel blanket are shown in Figure 2.

\section{Conclusion}

The presence of Maerogel on the glass wool hinders the heat transfer rate due to an increase in the amount of ash formation which consequently acts as a heat barrier. The thermal stability of the silica aerogel blanket was better compared to the OGW and $18.6 \mathrm{wt} \%$ was the highest loaded Maerogel that could be possible on the blanket. MGW was able to retard processing loss weight from 270 to $287^{\circ} \mathrm{C}$ and, at temperatures higher than $270^{\circ} \mathrm{C}$, the addition of silica aerogel reduced the rate of weight loss of the blanket. Aerogel blankets that are composites of silica aerogel particles dispersed in a reinforcing fiber matrix can turn the brittle aerogel into a durable and flexible insulating material.

\section{Competing Interests}

The authors declare that there are no competing interests regarding the publication of this paper.

\section{References}

[1] S. S. Kistler, "Coherent expanded aerogels," The Journal of Physical Chemistry, vol. 36, no. 1, pp. 52-64, 1932.

[2] A. C. Pierre and G. M. Pajonk, "Chemistry of aerogels and their applications," Chemical Reviews, vol. 102, no. 11, pp. 4243-4265, 2002.

[3] J. Fricke and T. Tillotson, "Aerogels: production, characterization, and applications," Thin Solid Films, vol. 297, no. 1-2, pp. 212-223, 1997.

[4] N. Bheekhun, A. R. Abu Talib, and M. R. Hassan, "Aerogels in aerospace: an overview," Advances in Materials Science and Engineering, vol. 2013, Article ID 406065, 18 pages, 2013.

[5] H. Halimaton, inventor; Google Patents, assignee, Silica Aerogels, 2007.

[6] C.-X. Zhao, Y. Liu, D.-Y. Wang, D.-L. Wang, and Y.-Z. Wang, "Synergistic effect of ammonium polyphosphate and layered double hydroxide on flame retardant properties of poly(vinyl alcohol)," Polymer Degradation and Stability, vol. 93, no. 7, pp. 1323-1331, 2008.

[7] X. Zhu, Y. Wu, C. Tian, Y. Qing, and C. Yao, "Synergistic effect of nanosilica aerogel with phosphorus flame retardants on improving flame retardancy and leaching resistance of wood," Journal of Nanomaterials, vol. 2014, Article ID 867106, 8 pages, 2014.

[8] E. R. Bardy, J. C. Mollendorf, and D. R. Pendergast, "Thermal conductivity and compressive strain of aerogel insulation blankets under applied hydrostatic pressure," Journal of Heat Transfer, vol. 129, no. 2, pp. 232-235, 2007.

[9] N. K. On, A. A. Rashid, M. M. M. Nazlan, and H. Hamdan, "Thermal and mechanical behavior of natural rubber latexsilica aerogel film," Journal of Applied Polymer Science, vol. 124, no. 4, pp. 3108-3116, 2012.
[10] H.-X. Zhang, X.-D. He, and F. He, "Microstructural characterization and properties of ambient-dried $\mathrm{SiO}_{2}$ matrix aerogel doped with opacified $\mathrm{TiO}_{2}$ powder," Journal of Alloys and Compounds, vol. 469, no. 1-2, pp. 366-369, 2009. 

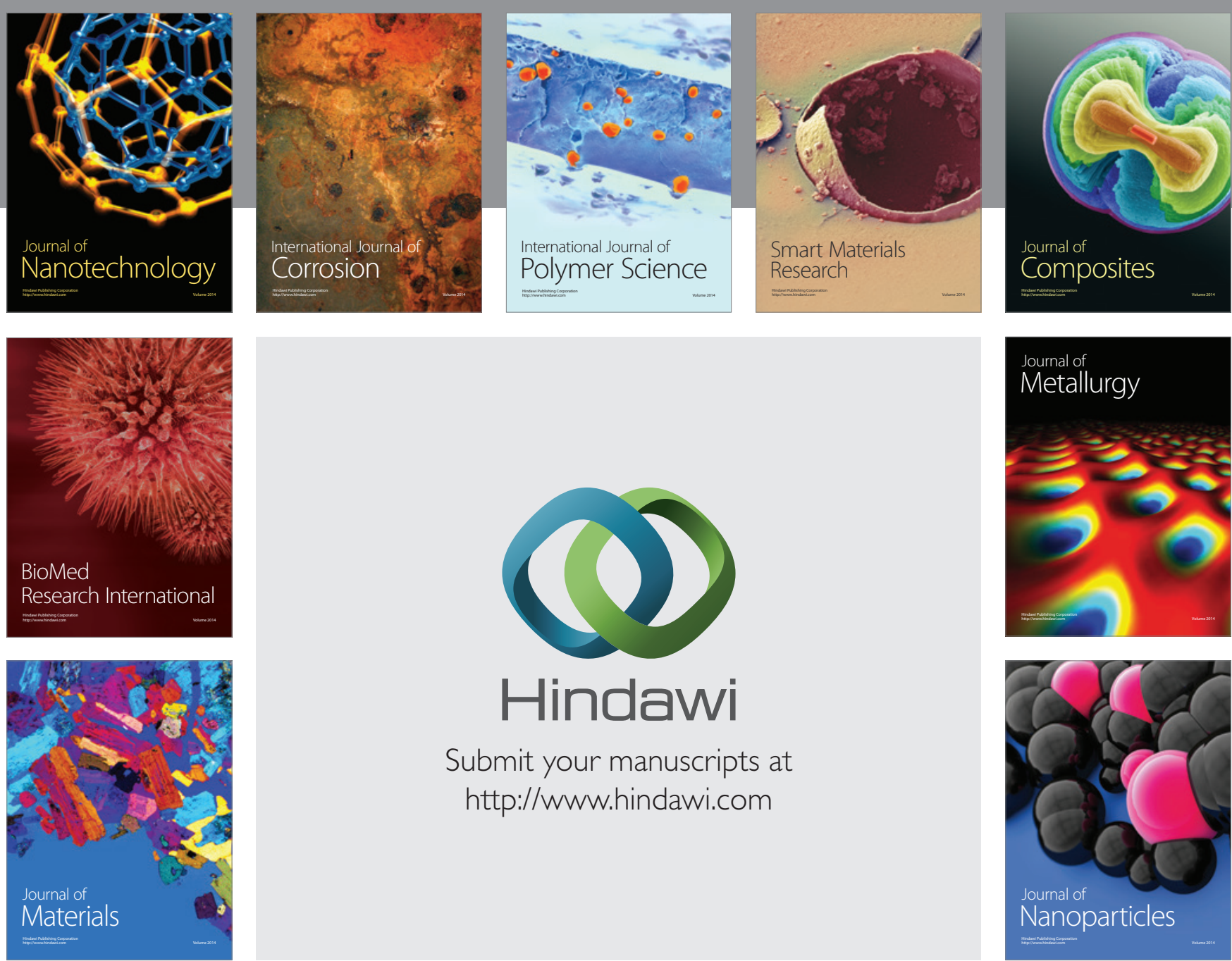

\section{Hindawi}

Submit your manuscripts at

http://www.hindawi.com

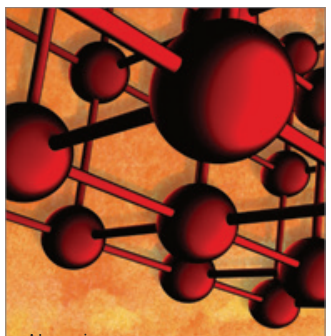

Materials Science and Engineering
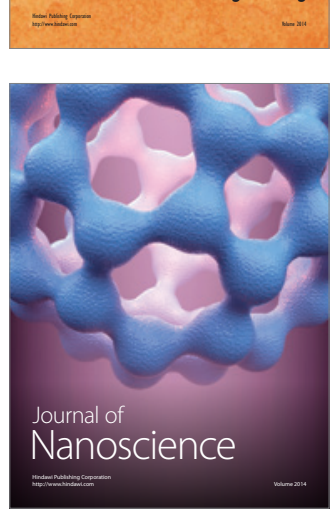
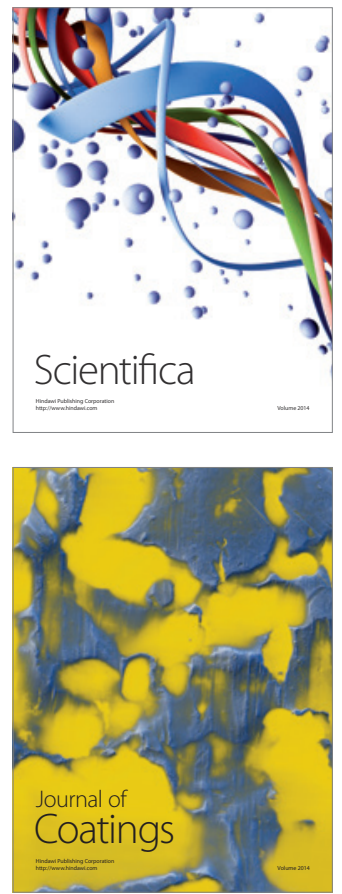
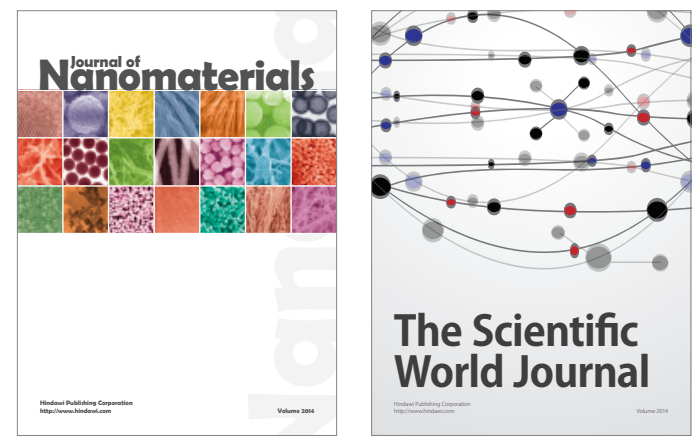

The Scientific World Journal
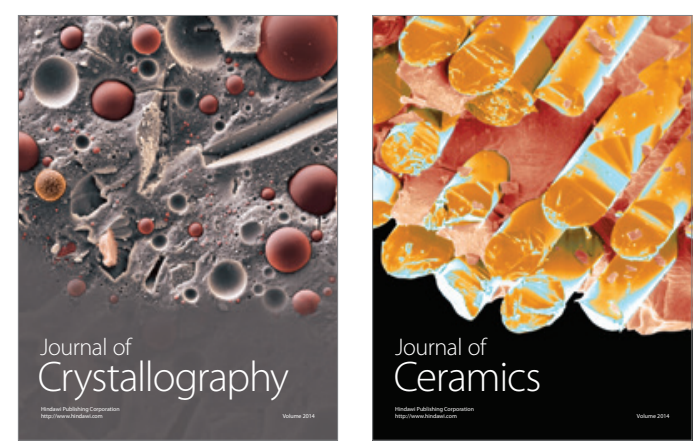
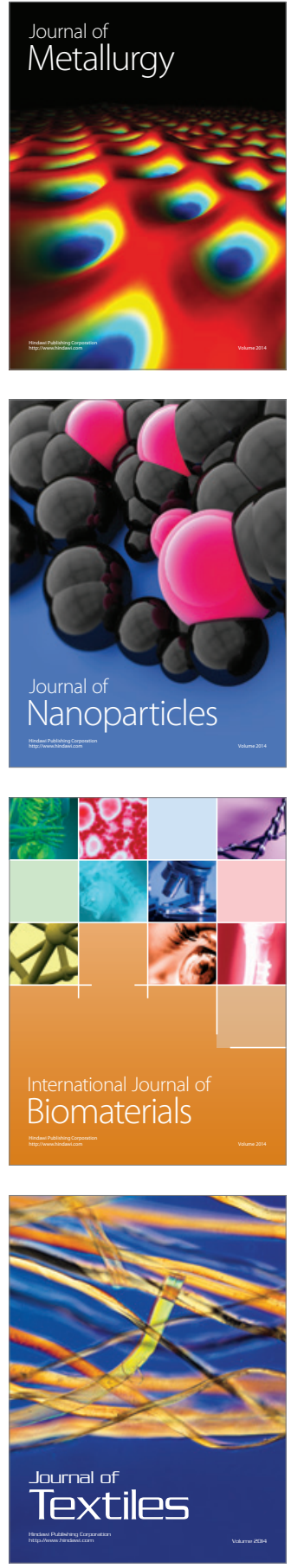